\title{
SOBRE O FUTURO CÓDIGO AMBIENTAL NA ALEMANHA*
}

\author{
MICHAEL KLOEPFER ${ }^{* *}$
}

\begin{abstract}
RESUMO: O artigo sintetiza alguns dos argumentos favoráveis e contrários à edição de um Código Ambiental. Em seguida, relata o caminho trilhado (e ao fim, sem sucesso) para a adoção de um Código Ambiental na Alemanha, sob o ponto de vista político e sob o aspecto das escolhas do legislador, tanto em relação ao conteúdo do Código, quanto em relação aos procedimentos para colocá-lo em vigor.

PALAVRAS-CHAVE: Código Ambiental; Alemanha; Estudo de Impacto Ambiental.
\end{abstract}

ABSTRACT: The article synthesizes the arguments favoring and disfavoring the edition of an Environmental Code. Next, it conveys the (ultimately unsuccessful) path leading to the adoption of an Environmental Code in Germany, from the political and legislative choices perspectives, and as regards the latter, relating both to the Code's content and the procedures aimed at passing it.

KEYWORDS: Environmental Code; Germany; Environmental Impact Assessment.

SUMÁRIO: A. Da discussão basilar sobre um Código Ambiental (CA); B. Os projetos precedentes de um CA; C. Legiferação Ambiental e Reforma do Federalismo I; D. Sobre o Projeto Oficial do Código Ambiental elaborado pelo Governo Federal; E. Conclusão.

SUMMARY: A. The basic discussion on na Environmental Code (EC); B. The preceding Projects of the EC; C. Environmental Legislation-making and the Federalism Reform I; D. On the Federal Government's Official Environmental Code Draft; E. Conclusion.

\section{A. DA DISCUSSÃO BASILAR SOBRE UM CÓDIGO AMBIENTAL (CA)}

O clamor por uma codificação de direito ambiental foi suscitado na Alemanha pela primeira vez em meados dos anos setenta do século passado. Em muitos países (como Finlândia, França, Holanda, Polônia, Suécia, Suíça, Inglaterra) sucederam-se desde então codificações de direito ambiental - completas ou parciais -, todavia não ocorrendo o mesmo até agora na Alemanha. Isso parece prestes a mudar. O debate de dez anos sobre uma codificação de direito ambiental na Alemanha ${ }^{1}$ suscitou alguns argumentos contra, mas muitos mais a favor de uma codificação.

Artigo recebido em 15.09.2008 e aprovado para publicação pelo Conselho Editorial em 30.03.2010.

* Traduzido por Ivar Alberto Martins Hartmann e revisado por Ingo Wolfgang Sarlet.

** Prof. Dr. Universidade Humboldt, Berlim.

${ }^{1}$ Assim, sobre o CA, exemplificativamente e por último: BMU (Ed.) Herausforderung Umweltgesetzbuch 2007; Bohne, EURUP 2006, p. 276 e ss.; Kloepfer, UPR 2007, p. 161 e ss.; do mesmo autor, Die Verwaltung 2008; do 


\section{Objeções a um CA}

Quando do início da discussão, verificava-se ceticismo em relação à codificiabilidade, especialmente em função da delimitação do direito ambiental ${ }^{2}$ e em relação ao reconhecimento do mesmo como campo autônomo da ciência do direito. Essas objeções foram nesse meio tempo (especialmente em razão de diferentes projetos de CA elaborados nesse interregno) superadas. Da mesma forma o argumento - um tanto quanto fundamentalista - de que, em uma democracia caracterizada por compromissos, as codificações sistemáticas como as do século XIX não mais são possíveis ${ }^{3}$, ou seja, a afirmação da antinomia entre codificação $e$ democracia, foi desqualificado após a $2^{\text {a }}$ Guerra, tendo em vista o advento de muitas codificações modernas (Lei de Organização da Justiça Administrativa, Lei do Processo Administrativo, Código Social etc.). Essas codificações mostram-se adequadas ao seu tempo e são caracterizadas por um nível médio de sistematização e abstração. Mais moderna é a objeção de que o direito ambiental europeu, relativamente assistemático, impediria uma codificação sistemática do direito ambiental nacional. O oposto é verdadeiro, como o exemplo das codificações de direito ambiental de outros países da União Européia têm demonstrado. Por meio de uma exitosa sistemática de um CA, é possível que a adaptação ao direito nacional das Diretivas Européias até corrija em parte o déficit de sistematização do direito comunitário. Por fim, não raro é sugerido como objeção o efeito fracionador que adviria de um CA. Isso, no entanto, é amplamente evitado por meio de uma moderada lapidação do CA, como, por exemplo, quando se exclui a matéria penal ambiental do $\mathrm{CA}^{4}$, com vistas à manutenção da unidade do Código Penal. Além disso, temem-se dificuldades de transição no que diz com a substituição da legislação esparsa por uma codificação. A despeito do fato de que tais dificuldades são superáveis com o uso de disposições transitórias, poder-se-ia, mediante a generalização de tais receios, objetar a praticamente todas as mudanças jurídicas, um resultado obviamente insustentável.

\section{Argumentos em prol de um CA}

Os numerosos argumentos em prol de uma codificação de direito ambiental são enumerados tão freqüentemente ${ }^{5}$ que aqui devem bastar algumas breves indicações. Uma codificação deverá primeiramente retificar as falhas do direito ambiental vigente, originado a partir de diversas etapas, ou seja, eliminar sua crescente dispersão,

mesmo autor, Umweltschutzrecht, 2008, p. 21 e ss.; do mesmo autor (Ed.), Das kommende Umweltgesetzbuch 2007; Lottermoser, UPR 2007, p. 401 e ss.; Rehbinder, KGV-Mitteilungen 2008, ; Sangenstedt, ZUR 2007, p. 505 e ss.; Szokalla, DVBl. 2008, p. 300 e ss.; Sellner, Dokumentation zur 31. Fachtagung der GfU 2007. p. e ss.; criticamente, Schrader, ZRP 2008, p. 60 e ss.; a respeito de perguntas isoladas, ver, por exemplo: Fischer-Hüftle, NuR 2008, s. 213 e ss.; Gärditz, Die Verwaltung 2007, p. 203 e ss.; Knopp, UPR 2008, p. 121 e ss.; Koch/Krohn, Das Naturschutzrecht im Umweltgesetzbuch, 2008.

${ }^{2}$ Kloepfer, Umweltrecht, $3^{\text {a }}$ Ed., 2004, § 1 número de margem 59 e ss..

${ }^{3}$ Como, por exemplo, Kübler, JZ 1969, p. 645 e ss.; em sentido contrário Kloepfer, JZ 1992, p. 817 (818).

${ }^{4}$ Para considerações conceituais de um CA ver, recentemente, por exemplo, Bohne, EurUP 2006, p. 276 (278 e ss.).

${ }^{5}$ Nesse sentido apenas Kloepfer, JZ 1992, p. 817 e ss.; Bohne, EurUP 2006, p. 277 e ss.; recentemente ainda Steinkemper, Das kommende Umweltgesetzbuch - Chancen, Konzepte und gegenwärtiger Stand des Gesetzgebungsprozesses, In: Kloepfer (Ed.), Das kommende Umweltgesetzbuch, 2007, p. 13 e ss.. 
obscuridade, afastar redundâncias e em parte também contradições valorativas, por meio de um trabalho legislativo não apenas formalmente unitário, mas também unitário em relação ao seu conteúdo. Por esse caminho torna-se possível alcançar a superação da super-normativização externa do direito ambiental (em função do excesso de leis) ${ }^{6}$. Além disso, uma codificação de direito ambiental possibilita, em termos ideais, a realização de uma concepção holística, integrada, de proteção do meio ambiente a partir da superação das estratégias de proteção específicas para cada meio, que são aplicadas no direito ambiental alemão tradicional ${ }^{7}$. A codificação possibilita alcançar um quadro normativo-legal ajustado e unificado, e, portanto, livre de contradições, além de terminologicamente harmônico, com o qual o legislador pode melhor realizar seu enfoque holístico da proteção ambiental ${ }^{8}$ - enfoque este advogado primeiramente e especialmente pela UE. Nessa medida, o CA pode tornar o direito ambiental alemão significativamente mais compatível com o direito comunitário. Ademais, uma codificação permite uma reforçada continuidade estrutural no direito ambiental, pois futuras modificações jurídicas precisarão adequar-se a conceitos sistemáticos pré-existentes. Um código ambiental já reduz a quantidade de normas de direito ambiental - ou seja, a super-normativização externa - simplesmente por dispensar regulamentações paralelas por meio de muitas leis isoladas. A sedimentação e enxugamento do direito e uma aprimorada harmonia são "dividendos da codificação" garantidos, que permitem expressivas simplificações processuais e maior facilidade na aplicação do direito pela Administração, como mostra o exemplo das licenças prévias integradas.

Não deve ser com isso negligenciado que a pretensão de uma desregulamentação no direito ambiental vai muito além, pois compreende também a diminuição da super-normativização interna, que foi levada a cabo nos últimos trinta anos especialmente por meio de normas excessivamente detalhadas e mesmo supérfluas. A codificação pode servir de fundamento para tais medidas de desregulamentação $e$ desburocratização. A diminuição da super-normativização depende, em última análise, do conteúdo do CA. Nessa medida trata-se aqui apenas de possíveis, todavia não garantidos, “dividendos da codificação”. O mesmo vale para a exigência, no CA, de um direito claro e de fácil aplicação. Independentemente disso a própria supressão da duplicidade de regras já leva a uma maior clareza do direito e facilita a aplicabilidade e executabilidade do direito ambiental. De maneira semelhante, uma modernização estrutural exitosa com uma codificação poderia ser fortalecida através de uma modernização de conteúdo. De maneira geral, um CA deve servir ao objetivo, formulado no direito comunitário, da “better regulation (melhor regulação)”. Uma codificação de direito ambiental de sucesso pode, por fim, gerar expressivos efeitos políticos. Ela pode influenciar de maneira integrada os diferentes campos da política ambiental, fortalecer a importância da política ambiental de maneira geral na Alemanha e com isso levar à reconquista pela Alemanha de sua - antiga - posição de (co)condutora no direito ambiental dentro da UE.

${ }^{6}$ Sobre o tema e tratando da diferenciação entre super-normativização interna e externa ver Kloepfer, VVDStRL, vol. 40 (1981), p. 68.

${ }^{7}$ Kloepfer/Kunig/Rehbinder/Schmidt-Aßmann, DVBl. 1991, p. 339 (339).

${ }^{8}$ Kloepfer, Umweltrecht, $3^{\text {a }}$ Ed., 2004, § 1, número de margem 42. 


\section{Conclusões Provisórias}

Em termos gerais a discussão técnica e política conduzida há alguns anos, sobre a fundamental conveniência do CA, pode ser certamente tida como resolvida. Os argumentos em prol de uma codificação superam - não apenas do ponto de vista da quantidade, mas também daquele do peso de seus conteúdos - os argumentos contrários, que foram em grande parte historicamente desqualificados (como o da falta de codificabilidade) ou afastados (como o das dúvidas de ordem constitucional). Em razão disso, não é surpresa que a opinião majoritária entre os cientistas do direito ambiental e praticamente todo o meio político passou a saudar o projeto de um Código Ambiental como tal. Isso naturalmente não exclui intensas controvérsias sobre determinadas partes do CA.

\section{B. OS PROJETOS PRECEDENTES DE UM CA}

A conveniência de um CA era discutida de maneira independente já nos anos setenta do século passado no âmbito da ciência jurídica. No relatório ambiental de 1976, do Governo Federal, foi aventada pela primeira vez a intenção do governo federal de averiguar a necessidade de apresentar uma obra legislativa unificada em matéria ambiental. Dois estudos encomendados pela autoridade federal ambiental ${ }^{9}$ investigaram a possibilidade de sistematização e harmonização do direito ambiental e concluíram que uma codificação de direito ambiental era possível e pertinente.

Em 1988, a autoridade federal ambiental criou um grupo de trabalho científico, formado por professores universitários, para a formulação de uma Parte Geral (PG CA) de um código ambiental, tendo o resultado sido publicado em 1990 no assim denominado Projeto dos Professores ${ }^{10}(C A-P G-$ ProjP). Um grupo ampliado de professores universitários elaborou então uma Parte Especial do Código Ambiental $(C A-P E)^{11}$. O Congresso de Juristas Alemães de 1992 aprovou o Código Ambiental ${ }^{12}$.

Em 1992 foi estabelecida a Comissão Independente de Especialistas para o Código Ambiental, pelo ministro federal de meio ambiente Klaus Töpfer, objetivando a articulação de um projeto de lei para um Código Ambiental. Quando da formação da nova edição da coalizão cristã-liberal Kohl/Genscher ${ }^{\mathrm{NT}}$, em 1994, foi pela primeira vez pactuado, mediante um acordo de coalizão, a criação de um código ambiental, um projeto que foi amparado pela então ministra federal do meio ambiente, Angela Merkel.

\footnotetext{
${ }^{9}$ Kloepfer, Systematisierung des Umweltrechts, 1978; Kloepfer/Meßeschmidt, Innere Harmonisierung des Umweltechts, 1986.

${ }^{10}$ Kloepfer/Rehbinder/Schmidt-Aßmann com a participação de Kunig, Umweltgesetzbuch - Allgemeiner Teil, 1991.

${ }^{11}$ Esboço de Kloepfer/Kunig/Papier/Peine/Rehbinder/Salzwedel/Schmidt-Aßmann, Umweltgesetzbuch Besonderer Teil, 1994.

${ }^{12}$ Verhandlungen des 59. DJT, 1992, Band II, Sitzungsberichte, Teil N.

${ }^{\mathrm{NT}} \mathrm{O}$ autor refere-se à aliança partidária formada para as eleições nacionais de 1994 na Alemanha. Nessa aliança uniram-se em coalizão mais uma vez os chamados Unionsparteien ou "partidos da união" ao partido FDP (Freie Demokratische Partei, Partido Liberal Democrata). Os “partidos da união” são dois partidos irmãos em nível federal, o CDU (Christlich Demokratische Union Deutschlands, União Cristão-Democrática Alemã) e o CSU (Christlich-Soziale Union in Bayern, União Cristã-Social da Baviera). Na época da coalizão, o líder nacional do CDU era Helmut Kohl, que foi em então reeleito chanceler da Alemanha. O líder honorário do FDP, e nome forte do partido, era Hans-Dietrich Genscher.
} 
O assim denominado Projeto da Comissão ${ }^{13}$ - composto por uma Parte Geral e uma Parte Especial - foi entregue em 1997 ao governo federal. Especialmente a Parte Geral cresceu expressivamente em relação ao Projeto dos Professores. O Projeto da Comissão deveria formar a base para um esboço por parte do Ministério Federal do Meio Ambiente, ou Projeto Oficial (PO).

Em 1998, durante a formação do primeiro governo federal vermelho e verde $(\text { Schröder/Fischer })^{\mathrm{NT}}$, sobreveio novamente um acordo de coalizão que reconhecia o projeto de um código ambiental. O Ministério Federal do Meio Ambiente, trabalhando em um CA, seguiu, entretanto, apenas de maneira limitada o enfoque geral do Projeto da Comissão e apresentou, em 1999, um esboço de um primeiro livro de um CA $(\mathrm{CA} \mathrm{I}-\mathrm{PO})^{14}$, que deveria servir de suporte especialmente também para a então urgente incorporação do direito comunitário, ou seja, da Diretiva PIP (Prevenção Integrada de Poluição) ${ }^{15}$ e da Diretiva AIA de alteração (Avaliação do Impacto Ambiental) ${ }^{16}$. Isso foi visto como primeiro passo em direção a uma abrangente codificação geral do direito ambiental. Com incertezas acerca de prerrogativas constitucionais em relação à suficiência da competência legislativa federal para uma codificação (sobretudo no que tange à gestão da água e à proteção da natureza, temas para os quais o Parlamento Federal, naquela ocasião, estava investido de competência apenas para legislar de maneira geral e não específica), o governo federal então sustou especialmente sob instigação dos Ministérios da Justiça e do Interior - o projeto do CA, apesar da opinião difundida ${ }^{17}$ de que o sustentáculo da competência que possuía então o Parlamento Federal já possibilitava legalmente a criação de um $\mathrm{CA}^{18}$.

O naufrágio temporário de um CA sob o então ministro federal do meio ambiente Jürgen Trittin foi lamentável também na medida em que em uma série de países europeus surgiram codificações (Holanda, Suécia, etc.) que haviam sido também inspiradas nos trabalhos preparatórios alemães para uma codificação ambiental. A renovada inclusão da criação de um código ambiental, sob base constitucional alterada, como termo da re-edição do acordo de coalizão governamental Schröder/Fischer, em 2002, restou sem consequências práticas.

${ }^{13}$ Bundesministerium für Umwelt, Naturschutz und Reaktorsicherheit (Ed.), Umweltgesetzbuch (UGB KomE), 1998.

${ }^{\mathrm{NT}} \mathrm{O}$ autor refere-se à coalizão vermelho e verde - Röt-Grüne Koalition - uma aliança entre o partido SPD (Sozialdemokratische Partei Deutschlands, Partido Socio-democrático Alemão), de esquerda, e o Partido Verde (Bündnis 90/Die Grünen, partido resultante da fusão, em 1993, de dois partidos verdes) para as eleições nacionais de 1998 na Alemanha. A coalizão venceu as eleições, tornando-se chanceler alemão Gerhard Schröder (líder do SPD a partir de 1999) e vice-chanceler e ministro de relações exteriores o porta-voz do Partido Verde, Joschka Fischer.

${ }^{14} \mathrm{O}$ esboço resultante dos trabalhos em um CA I de 05.03.1998 foi veiculado em Rengeling (Ed.), Auf dem Weg zum Umweltgesetzbuch, 1999, p. 273 e ss.; Um apanhado geral é dado por Schmidt-Preu $\beta$, DVBl. 1998, p. 857 e ss..

15 Diretiva 96/61/CE sobre a prevenção e redução integrada de poluição ambiental (Amtsblatt der Europäischen Gemeinschaften L 257 vom 10.10.1996, p. 26-40).

${ }^{16}$ Diretiva modificadora relativa à avaliação do impacto ambiental de determinados projetos públicos e privados 97/11/CE (Amtsblatt der Europäischen Gemeinschaften L 73 vom 14.03.1997, p. 5-15).

${ }^{17}$ Rehbinder/Wahl, NVwZ 2002, p. 21 (23); Kloepfer, Umweltrecht, 3. ed., 2004, § 3, número de margem 89 e ss..

${ }^{18}$ Sobre a crítica a essa razão oficial, ver possivelmente apenas Bohne, EurUP 2006, p. 276 e ss.. 
$\mathrm{O}$ atual governo federal da Grande Coalizão (Merkel/Müntefering) ${ }^{\mathrm{NT}}$ está providenciando a instituição de um CA. A Grande Coalizão acordou neste sentido desde que as premissas jurídico-constitucionais estivessem presentes. Com a Reforma do Federalismo I (ver sobre isso ponto 'C') isso acabou sendo alcançado.

A história do Código Ambiental - aqui apenas brevemente esboçada - mostra duas coisas:

1. O projeto do CA foi e tem sido levado adiante mediante amplo consenso dos partidos, inclusive de oposição.

2. O projeto de codificação ambiental certamente é um dos projetos legislativos melhor - e mais longamente - preparados na Alemanha até hoje.

\section{LEGIFERAÇ̃̃O AMBIENTAL E REFORMA DO FEDERALISMO I}

Como as bases constitucionais anteriores representavam o motivo oficial para o naufrágio do projeto do CA em 1999, o novo sistema de competências legislativas implementado por meio da Reforma do Federalismo $\mathrm{I}^{19}$, vigente a partir de $1^{\mathrm{o}}$ de setembro de 2006, ofereceu a pré-condição e a causa para a retomada do projeto de CA. As fortes maiorias da Grande Coalizão no Bundestag (Câmara de Deputados) e no Bundesrat (espécie de Senado, representando os estados) facilitaram a realização desta ampla reforma constitucional.

Com a Reforma do Federalismo I, que pela primeira vez criou plenas competências para o legislador federal também no âmbito do direito das águas e da proteção da natureza, criava-se então a possibilidade jurídico-constitucional de implementação de um código ambiental federal com normas sobre todas as matérias nucleares de direito ambiental $^{20}$ e também para a regulamentação de um processo nacionalmente unificado e integrado de autorização de estabelecimentos, que até então já deveria formar, no sentido de uma concepção de licença ambiental integrada, o núcleo da codificação de um código ambiental ${ }^{21}$. A Lei Fundamental alemã passa então - no sentido de uma expectativa constitucional - a contar com a expedita aprovação de um código ambiental no mais tardar até o final de 2009.

O direito ambiental comunitário, que nesse meio tempo prevalece entre os Estados-membro da UE, pode, com base na Reforma do Federalismo I, ser incorporado de maneira simplificada pelo governo federal. Com isso podem ser evitados os, até aqui frequentes, problemas de prazo dessa modificação no âmbito do Estado Federal alemão.

A despeito de alguns pontos problemáticos, o avanço representado pela Reforma do Federalismo I, tanto para o sistema federativo como um todo, quanto também para a proteção ambiental em especial, é incontestável. Um código ambiental, como um

NT A Grande Coalizão é como foi denominada em 2005 uma aliança entre os “partidos da união” (CSU e CDU) e o SPD. Essa coalizão venceu as eleições nacionais, tornando-se Angela Merkel, a líder do CDU, chanceler alemã e Franz Müntefering, líder do SPD, vice-chanceler e ministro do trabalho e do social.

${ }^{19}$ Lei de Alteração à Lei Fundamental, de 31.06.2006 (BGBl I, p. 2034).

${ }^{20}$ Ver sobre isso Kloepfer, Scholz-Festgabe, 2007, p. 651 e ss.; Schulze-Fielitz, NVwZ 2007, p. 255 e ss..

${ }^{21}$ Kloepfer, Umweltrecht, $3^{\mathrm{a}}$ Ed., 2004, § 4, número de margem 76; Kahl/Diederichsen, NVwZ 2006, p. 2801 e ss.. 
requisito substancial de um direito ambiental moderno, é assim legalmente viabilizado e, além do mais, recebe da Constituição uma salutar instigação política, pois o código ambiental foi precisamente o motivo da emenda constitucional. Os estados alemães podem fazer uso de suas prerrogativas de legislar de maneira discrepante (sobretudo no campo do direito das águas e da proteção da natureza) apenas a partir de $1^{\circ}$ de janeiro de 2010, conforme o art. 125b, número 1, frase 3, da Lei Fundamental. Isso irá incentivar o governo federal a, até tal ocasião, realizar uma codificação de direito ambiental que abrange os referidos temas, e que significará especialmente as primeiras regulamentações integrais na seara de direito das águas e do direito de proteção da natureza realizadas pelo governo federal na história da República Federativa da Alemanha.

Com isso, a Reforma do Federalismo I, também e já agora, sob o ponto de vista da proteção ambiental, revela-se como parte de um sustentável planejamento político geral na Alemanha. A Grande Coalizão, atualmente no poder, foi resoluta na inclusão em seu pacto de coalizão não apenas da reforma constitucional, mas também na sua colocação em prática mediante a instituição de um código ambiental.

\section{SOBRE O PROJETO OFICIAL DO CÓDIGO AMBIENTAL ELABORADO PELO GOVERNO FEDERAL}

\section{Trâmites Políticos e Estrutura da Lei}

Após a entrada em vigor da Reforma do Federalismo I, o Ministério do Meio Ambiente trabalhou intensamente para a elaboração de um código ambiental: um grupo de projeto do Ministério, no qual trabalhavam a divisão central e outros departamentos, apresentou um Projeto Oficial (PO) em novembro de $2007^{22}$, com o qual o gabinete do Governo Federal deverá concordar no verão de 2008, devendo ser aprovado pelo Parlamento até final de 2008. Presentemente toma lugar a discussão entre os Ministérios Federais.

O Governo Federal, com o Projeto Oficial de CA (PO), em virtude das possibilidades temporais limitadas no corrente período legislativo, de maneira alguma almeja uma codificação extensiva, mas sim apenas o regramento dos assuntos: provisões gerais (especialmente sobre a licença ambiental integrada), direito da proteção da natureza, direito da proteção contra imissões e direito de proteção das águas. A inclusão dos "Livros" ainda faltantes deve seguir-se nos próximos períodos legislativos. Neste sentido, adotou-se a concepção de uma “codificação seriada” (ver abaixo).

O Ministério do Meio Ambiente introduziu recentemente, com o Projeto, uma codificação parcial (CA-Nuclear) constituída de seis “Livros” (com ao todo 397 parágrafos):

CA Primeiro Livro: Provisões gerais e direito ambiental relacionado a projetos de estabelecimentos (CA I - PO) - com 10 anexos

CA Segundo Livro: Economia das Águas (CA II - PO)

CA Terceiro Livro: Proteção da natureza e da paisagem natural (CA III - PO)

\footnotetext{
${ }^{22}$ http://www.bmu.de/gesetze_verordnungen/umweltgesetzbuch/doc/40448.php, Acesso em: 3 dez. 2007.
} 
CA Quarto Livro: Radiação não-ionizante (CA IV - PO)

CA Quinto Livro: (Direito do) Comércio de Emissões (CA V - PO) - com 3 anexos

CA Sexto Livro: (Direito das) Energias Renováveis (CA VI - PO) - com 7 anexos; está providenciada aqui a pré-adoção da Lei de Energias Renováveis, que por força da Lei Introdutória ao Código Ambiental deve ser convertida em CA VI.

Com essa separação entre regulamentações gerais no CA I - PO e partes especialmente orientadas (CA II-VI - PO) o PO na verdade assume de certa forma, embora em versão mais "fraca”, a estrutura básica do Projeto dos Professores e do Projeto da Comissão em uma Parte Geral e uma Parte Especial. Nessa medida ele permanece na tradição das grandes codificações sistemáticas na Alemanha (por exemplo o BGB - Código Civil e o StGB - Código Penal), sem sucumbir ao perigo de uma abstração demasiada nas disposições.

Os livros ainda faltantes (especialmente sobre o direito dos estabelecimentos não dependentes de licenciamento, sobre a proteção contra imissões relacionada às áreas e ao tráfego, sobre a proteção do solo e locais historicamente contaminados, sobre o direito da gestão da reciclagem e dos dejetos, sobre a proteção contra substâncias perigosas, sobre requerimentos em relação a produtos e proteção de recursos, assim como, conforme o caso, sobre a proteção contra radiação ionizante) devem ser adicionados nos próximos períodos legislativos. Não está previsto, até agora, mesmo a médio ou longo prazo, a inserção do direito da energia atômica no CA, pois conforme o direito vigente, o uso civil de energia atômica deve ser descontinuado na Alemanha nos próximos anos. Isso pode modificar-se caso a Câmara dos Deputados, após uma nova eleição, no próximo período legislativo, venha a se decidir por uma retomada do uso civil de energia atômica.

Também regramentos gerais sobre a administração ambiental pelo Governo Federal (como nos $\S \S 613$ e ss. da Parte Geral do Projeto dos Professores, $\S \S 54$ e ss. do Projeto da Comissão) não estão até o momento previstos no Projeto Oficial. Da mesma forma não estão - até agora - previstos regramentos abrangentes dos instrumentos indiretos (de política ambiental), especialmente dos instrumentos econômicos. Como corpo normativo, o Projeto Oficial é necessariamente lacunoso.

A estratégia do andamento seriado no $\mathrm{CA}^{23}$ (algo conforme o paradigma do direito ambiental da Holanda ou, por exemplo, também do Código Social Alemão) tem, sobretudo, a vantagem da viabilidade política facilitada. Ela possibilita um avanço nos trabalhos de codificação mesmo com recursos temporais e pessoais limitados no âmbito do processo legislativo. Como os livros são, em si mesmos, leis autônomas, apresentam-se vantagens - da perspectiva do governo federal - decorrentes da necessidade de aprovação apenas parcial, e relativa a cada livro, pelo Bundesrat (Câmara Alta). Ademais, por meio da codificação seriada podem ser afastadas do CA soluções polêmicas do direito vigente anterior, sem que com isso elas sejam abrogadas.

${ }^{23}$ Ver sobre isso Kloepfer, Die Verwaltung 2008, p. e ss.; do mesmo autor, Umweltschutzrecht, 2008, p. 25 e ss.. 
A estratégia de um processo seriado tem naturalmente também a desvantagem de que, durante o tempo de concepção, deve-se abdicar das benesses de uma codificação completa, de tal sorte que a intensidade da codificação resulta mais reduzida. O conceito do processo seriado deve garantir, nos primeiros capítulos, especialmente a "capacidade de acoplamento" das futuras partes do CA.

Imprescindível é, de qualquer modo, uma Lei de Introdução ao CA, que durante um intervalo de transição colocará ordem na coexistência de direito antigo e novo, assim como nas modificações que se seguirão em outras leis. Um projeto foi elaborado por especialistas nomeados pelo Ministério do Ambiente e apresentado ao final de 2007.

O Projeto Oficial de CA contém simultaneamente dois esboços de decretos executivos, um para a regulamentação de projetos (com a determinação dos requisitos para permissões relativas ao mesmo projeto específico) e um sobre os oficiais ambientais em empresas e agências.

Sob o aspecto do conteúdo o CA I - PO é certamente o mais significativo livro do Projeto Oficial de $\mathrm{CA}^{24}$. Ele tem a função de uma - relativamente enxuta - Parte Geral. O CA I - PO é composto por três capítulos (disposições comuns, licença ambiental integrada, disposições finais), que são, por sua vez, fracionados em seções e subseções. O CA I - PO prevê 10 anexos (verdadeiramente novos: anexos 8-10) assim como os já mencionados esboços para 2 decretos executivos no Projeto Oficial do CA.

\section{Em Especial: A Licença Ambiental Integrada}

Nesse espaço pode ser apresentado apenas o segundo capítulo do CA I - PO, sobre a Licença Ambiental Integrada (§§ 47-137 CA I - PO). Este é o coração do CA I - PO. Esse capítulo regula um novo e unificado tipo (reunindo especialmente o direito da proteção contra imissões e o direito das águas) de autorização da Licença Ambiental Integrada (LAI) para determinados projetos ambientalmente e espacialmente significativos, ou seja, especialmente para determinadas instalações e para o uso particularmente intensivo de água. A LAI é concedida por uma autoridade em um processo unificado, desenvolvendo assim um forte efeito de integração e possibilitando uma única decisão homogênea. Ela reúne especialmente regras da Lei Federal de Proteção contra Imissões (Bundesimmissionsschutzgesetz), na 9a Ordenança Federal sobre Proteção contra Imissões (Bundes-Immissionsschutz-Verordnung), da Lei de Avaliação Ambiental (Gesetz über die Umweltverträglichkeitsprüfung), da Lei de Processo Administrativo (Verwaltungsverfahrensgesetz), da Lei de Gestão da Água (Wasserhaushaltsgesetz), da Lei de Reciclagem e Dejetos (Kreislaufwirtschafts- und Abfallgesetz) e da Lei Federal de Proteção do Solo (Bundesbodenschutzgesetz) e corresponde otimamente aos requisitos de uma proteção ambiental integrada. Na verdade ela irá acelerar a centralização das autoridades concessoras de licenças.

A LAI substitui - em primeiro lugar - como autorização, as presentes autorizações, permissões e licenças (no âmbito do direito da proteção contra imissões

\footnotetext{
${ }^{24}$ Sobre o conteúdo do PO - CA de maneira geral Kloepfer, Die Verwaltung 2008, p. e ss.; especialmente sobre o CA I - PO, idem, p. 207 e ss. assim como, do mesmo autor, Umweltschutzrecht, p. 28 e ss..
} 
e do direito das águas) e - em segundo lugar - como autorização para o planejamento, as presentes autorizações oficiais de projetos para planos específicos com demanda de espaço (depósitos de lixo, sistemas de tubulação, reservatórios artificiais de água, tratamento de água, diques e seu desenvolvimento).

Os requisitos da avaliação ambiental em análises de projetos estarão, naqueles planos cuja avaliação ambiental é obrigatória, inseridos no processo de obtenção da autorização. O recurso à Lei de Avaliação Ambiental é, nessa medida, inaplicável. A despeito disso, as permissões de outros projetos (por exemplo, a construção de ruas e ferrovias ou os projetos florestais) seguem submetidas ao direito especial e à existente Lei de Avaliação Ambiental.

Ao passo que a LAI, de regra, prevê uma participação pública nos procedimentos, o capítulo contém também disposições sobre um processo simplificado (sem participação pública).

A compulsoriedade da LAI é regulada de modo geral pelo § 49 CA I - PO e em concreto pelo Decreto Executivo de regulamentação de projeto, que foi adicionado ao PO - CA como esboço. A classificação geral dos atuais tipos de projetos aos processos de autorização é regrada pelo $\S 50$. A classificação detalhada de tipos individuais de projetos às categorias de avaliação ambiental, avaliação ambiental estratégica, processo de avaliação preliminar, autorização, autorização de planos - ou autorização em procedimentos simplificados, mas também gestão de emissões, é efetuada por esse decreto executivo de regulamentação de projetos (com um esquema-matriz unificado).

A conformação na condição de uma autorização unificada por meio de uma autoridade em um processo requer para a LAI pressupostos fáticos de autorização extensivamente uniformizados (§ 54). A LAI no formato da autorização é, com isso, configurada como um ato administrativo vinculado e sindicável. No entanto, a particular escassez da água conduz à necessidade de administração pelo Estado, motivo pelo qual a LAI, como autorização para uma utilização autônoma de água (como projeto) ou uma utilização de água como parte de um projeto, é colocada, nessa medida, no âmbito da adequada discricionariedade administrativa. A LAI como autorização de planos situa-se, em razão de seus elementos de ponderação, no âmbito da discricionariedade da Administração.

\section{Avaliação e Perspectivas}

O novo CA poderá ser definitivamente avaliado apenas após sua entrada em vigor e acima de tudo após sua afirmação na prática. A seguinte avaliação preliminar do $P O$ - $C A$ como um todo parece, no entanto, viável: Ainda que o Projeto, de modo geral, em uma ou outra parte, permaneça aquém das possibilidades no que diz com a intensidade de codificação e de inovação do Projeto dos Professores e do Projeto da Comissão (e certamente o deveria, por razões de tempo), e mesmo que requeira uma série de melhorias formais e materiais isoladas (por exemplo, mesma forma estrutural em todos os Livros), ele mostra já muito claramente o potencial de otimização, harmonização e racionalização de uma codificação de direito ambiental. No geral podem ser dados como acertados especialmente o conceito de Licença Ambiental 
Integrada, assim como o CA II - PO (direito das águas) e o CA III - PO (direito da proteção ambiental). O CA V - PO (gestão das emissões) e o CA VI - PO (energias renováveis) compreendem na prática apenas inclusões de leis já existentes. O CA IV - PO é (parcialmente) original, mas por pouco chega a preencher um "Livro" no CA. Os anexos ao CA I - PO (particularmente 8-10) e o planejado Decreto Executivo sobre projetos facilitarão a aplicabilidade do CA. O PO - CA poderia com isso ser, no todo, um passo promissor em direção à necessária codificação do direito ambiental alemão. O processo de codificação no direito ambiental alemão ganha, de qualquer modo, impulso.

No momento, as perspectivas para um CA seguem de modo geral relativamente favoráveis: As dúvidas de ordem constitucional estão afastadas, as maiorias políticas seguem mantidas na sua essência e a pressão temporal para agir, resultante do final do período legislativo - mais precisamente, da moratória jurídico-constitucional em relação à prerrogativa dos estados de legislar de maneira discrepante - podem evitar uma discussão interminável do projeto. Até a programada entrada em vigor de um Código Ambiental ao final de 2008 resta seguramente ainda um caminho significativo a ser percorrido, durante o qual a maioria dos obstáculos (como interesses coletivos contrapostos dos grupos de interesse organizados ou auto-promoção político-partidária no final do período legislativo) ainda precisa ser contornada.

Para garantir o êxito do CA era politicamente significativo limitar, na maior extensão possível, o CA-Nuclear à competência departamental do Ministério Federal do Meio Ambiente. As divisões temáticas entre os ministérios de meio ambiente foram racionalmente incluídas de forma precoce - o que se sucedeu por meio dos mencionados grupos de projetos -, para inibir possíveis oposições ao CA por parte de "irmandades de experts" burocráticas dentro dos ministérios. Também os estados foram de antemão incluídos, especialmente para assegurar a adesão do Bundesrat ao CA e para manter o mais baixo possível o potencial de uma posterior legiferação discrepante pelos estados. Os estados formaram também muito rapidamente um “Grupo de trabalho CA” próprio, na Conferência (permanente) de Ministros de Meio Ambiente $^{25}$. Grupos de trabalho do CA similares são também conhecidos no âmbito das associações privadas. Um grupo no âmbito do Ministério Federal do Meio Ambiente deveria garantir a inclusão antecipada de associações trabalhistas e científicas, autoridades executivas e cientistas no trabalho desse Ministério. Isso fez com que ao menos aparentemente - nenhuma crítica de déficit em termos de participatividade durante o trabalho no PO - CA tenha sido suscitada.

Para as discussões políticas remanescentes no Parlamento afigura-se como indispensável mais uma referência. A codificação não deve ser utilizada, em hipótese alguma, como veículo para uma fundamental alteração do nível de proteção do meio ambiente (tanto acréscimo como decréscimo), ainda que isso possa ser tentador para uma ou para outra parte. Pois então os atuais opositores de tal alteração automaticamente (e sem necessidade) se tornariam opositores da própria codificação. As associações ambientais, por exemplo, iriam posicionar-se contra um código ambiental que diminuísse

${ }^{25}$ Conclusão da Conferência de Ministros do Meio Ambiente de 23-24.05.2006. 
o nível de proteção, da mesma forma que as associações da indústria e do comércio iriam posicionar-se contra um que aumentasse o nível de tutela ambiental. Funcionando a codificação no patamar do nível de proteção atual, conforme esperado, já seria um aprimoramento significativo da proteção ambiental, pois o direito ambiental vigente tornar-se-ia mais bem executável. As capacidades desobstruídas da Administração na seara ambiental poderiam servir à melhor execução do direito ambiental simplificado.

\section{E. CONCLUSÃO}

No interesse da proteção ambiental e da capacidade de reformas da Alemanha é de se esperar que a luta de mais de trinta anos por um CA alemão tenha um final feliz. Levando em consideração a duração dos trabalhos preparatórios, o CA é no momento certamente o projeto de lei mais intensivamente preparado da Alemanha. É possível alcançar, até 2009, uma importante etapa com o CA-Nuclear ${ }^{26}$. O objetivo final, o CA completo, pode então ser realizado mediante a colocação em pauta dos “Livros” ainda faltantes nos próximos períodos legislativos. O CA não se trata de uma codificação apenas pela codificação. A decomposição da super-normativização externa, a sistematicidade e a harmonização aprimorada, assim como a fortalecida continuidade estrutural no direito ambiental são dividendos virtualmente garantidos da codificação. A reversão da super-normativização interna, o fortalecimento da auto-regulação societária, a desburocratização, a inovação qualitativa e a maior aptidão para respeitar o direito comunitário são, caso seja alcançado o conteúdo adequado do CA, possíveis dividendos da codificação. As benesses virtualmente garantidas ou possíveis da um CA representam um genuíno lucro para todos os participantes. O futuro significa: realização de oportunidades. Daí porque o CA ao futuro pertence*.

\footnotetext{
${ }^{26}$ Sob uma perspectiva otimista poderia o CA inteiro ser aprontado até 2013. Até lá dar-se-á uma (ordenada) sobreposição de direito ambiental antigo e novo. Uma lei de introdução ao CA deverá prever normas de transição.

* O presente texto foi finalizado pelo autor no primeiro semestre de 2008. Infelizmente, no início da legislatura de 2009, o rompimento da coligação CDU, especialmente CSU e SPD (evidentemente por interesses partidários na ascensão ao Poder) levou ao fracasso da edição do projeto de Código Ambiental, apesar das intensas consultas entre os Ministérios Federais, os Estados federados e os grupos de interesses em causa - entre eles, a indústria e ONGs ambientalistas - não foi possível chegar a um consenso. O Ministério do Meio Ambiente alemão está agora a tentar transferir a regulamentação prevista nos Livros I-IV relativas à água, proteção da natureza e proteção contra as radiações para leis gerais a serem editadas no curso do processo parlamentar. No início de fevereiro de 2009, o Ministério já iniciou a coordenação interministerial sobre estas leis. Após a conclusão dessas medidas legislativas imediatas, a legislação ambiental deve continuar a ser desenvolvida com base em leis individuais para enfrentar os desafios atuais da proteção ambiental. No entanto, a ausência de um código ambiental como a base e enquadramento da legislação ambiental fará este trabalho mais difícil.
} 